\title{
Prevalence of vibration-induced white finger in fluorspar mines in Weardale
}

\author{
D. S. CHATTERJEE 1 , A. PETRIE ${ }^{2}$, AND W. TAYLOR 3
}

From the ${ }^{1}$ British Steel Corporation, Consett, County Durham, the ${ }^{2}$ Department of Occupational Health and Hygiene. University of Newcastle upon Tyne, and the ${ }^{3}$ Wolfson Institute of Occupational Health, University of Dundee

ABSTRACT A combined epidemiological and clinical study of vibration-induced white finger (VWF) was carried out involving 115 men in four fluorspar mines. The overall prevalence of VWF was found to be $50 \%$ among 42 vibration-exposed subjects, while that of constitutional white finger (CWF) was $5.6 \%$ in all men studied. The VWF latent interval was $1-19$ years with a mean of 5.6 years. An association was observed between the exposure time and VWF stages which included 18 men in Stage 0, three in the intermediate stage of $0_{\mathrm{T}} / 0_{\mathrm{N}}$, five in Stage 2 and 16 in Stage 3; no men were seen at Stage 1. Among those with VWF in Stage 3, the index, middle and ring fingers were affected in both hands and the little fingers and thumbs were last to be involved. Clinically, on general examination, apart from vibration-induced white finger, the men in the 'vibration' group were as healthy as those in the 'control' group. The circumference of the index fingers was not significantly different for the different groups. Neurological tests showed that the ridge test and, to a lesser extent, the two-point discrimination and the light touch tests, could be regarded as useful for the diagnosis of VWF.

Mining in the Northern Pennines is known to have been in progress soon after the Norman conquest. In the twentieth century, lead mining in this area has been at its lowest ebb, but this has been compensated to some extent by the development of fluorspar mining which was originally started in 1882 (Dunham, 1949). Modern technology and wet drilling have minimised the incidence of occupational lung diseases but, on the other hand, percussion tools have created another hazard among the rockdrillers, namely vibration-induced white finger (VWF) or Raynaud's phenomenon of occupational origin. Although the use of pneumatic tools has been known since 1839 in the French mines (Schumacher, 1972) its association with the symptoms in the hands was not reported until 1911 (Hunter, 1969). In 1862 Dr Maurice Raynaud in his MD thesis 'De l'Asphyxie Locale et de la Gangrène Symétrique des Extrémités' described seven different conditions in which he had found the phenomenon of intermittent

${ }^{3}$ Present address: National Institute of Occupational Safety and Health, Cincinnati, Ohio, USA.

Received for publication 3 March 1978

Accepted for publication 10 March 1978 attacks of pallor or cyanosis of the extremities. According to modern medical literature Raynaud's disease is a well-defined clinical entity without any known associated and contributing conditions or disease, a typical example being constitutional white finger (CWF). When a similar syndrome is caused by vibration or associated with occlusive vascular disease, neurogenic lesions, certain types of poisoning, dysglobulinaemia, scleroderma or other conditions it is termed secondary Raynaud's phenomenon. The aetiology of VWF is based in general on two main theories, the neurovascular theory and the callus theory; however, as the latter still awaits pathological and clinical confirmation, most of the clinical tests so far have been directed towards the former. In 11 forestry workers with known traumatic vasospastic disease, Hellstrøm and Myhre (1971) provoked Raynaud's phenomenon by combined general and local exposure to cold; the production of attacks was apparently facilitated by hand grip. Taylor and Pelmear (1975) reported the validity of a series of clinical tests, of which only the depth sense aesthesiometer or ridge test gave a significant statistical 
difference between the vibration and the control groups. Renfrew (1969) described the fingertip as the fovea of the skin. He endeavoured to show that the threshold for the somatic sense of space in the right-angled plane was much lower than that in the parallel plane, and suggested that related tests such as the two-point discrimination (TPD) and the ridge tests should be routine in all neurological examinations. Against this background, our aim was to carry out controlled comparative epidemiological and clinical studies to measure the prevalence of VWF and the associated sensory changes in the hands of rock-drillers exposed to vibration. Concurrently, a general medical examination was performed to exclude other causes of Raynaud's phenomenon.

\section{The mines and the miners}

Four fluorspar mines, Blackdene, Groverake, Whiteheaps and Beaumont, were included in the survey. The first two mines are the main producers; Whiteheaps is predominantly a processing plant and Beaumont is a new development based on the former Allenheads lead mine.

The veins in these mines are normally about 2 metres wide, vertical and occur in limestone or sandstone. Mine air temperatures average about $10^{\circ} \mathrm{C}$ over all the mines and fluctuate very little between the seasons. The extremely wet surroundings and low air flow (maximum 5000 cubic feet $\left(\approx 142 \mathrm{~m}^{3}\right)$ per minute near the booster fans) combine to produce $100 \%$ relative humidity virtually everywhere.

The fluorspar miners normally work in pairs, at any one time on up to eight faces, either production 'headings' and 'stopes' or exploratory 'rises'. Apart from the face workers, other underground personnel are involved in shot firing and haulage of materials. In recent years most of the workings underground have been either in sandstone or in limestone, except in Blackdene mine, where limestone and whin sill works have predominated. Whin sill is an igneous rock and is one of the hardest to drill; this has been confirmed by a series of scleroscopic and crushing tests during the survey.

The day-to-day work of the miners follows a consistent pattern. The initial task involves clearing the working area of loose rock brought down by the previous day's blasting. In areas accessible to rail tubs, this is accomplished by the use of compressedair-powered back-loaders which transfer material direct from ground to tubs. In other areas, material is transferred to vertical chutes ending in hoppers at the main haulage level. In the latter case the handling of loose rock is accomplished by remote-controlled wire-mounted scrapers or by manual shovelling. After the debris has been cleared, shot holes (about
19-25 holes in an average face) are drilled in the exposed face, using pneumatic equipment (rockdrills about $1.2-1.8 \mathrm{~m}$ long) with water applied to the drill bit to suppress dust. Finally, charges are placed in the drill holes in each face and detonated by the shot-firer.

Outside the mine, crude ore is crushed and graded in a wet screening plant from which galena (lead sulphide) is recovered. Fluorspar, both crude and metallurgical grade, is the main product of the mines.

\section{Vibration characteristics of the rock-drills}

Two types of percussive drills, the Holman $303 \mathrm{H}$ and the Ingersoll T300, are used. However, the Holman drill is used more often in the Whiteheaps, Groverake and Beaumont mines, while use of the Ingersoll drill is more common at Blackdene. The drilling is carried out for 12 hours on average with a range of 2-23 hours per week. Both of these drills have combined rotatory and hammering actions and are known to produce noise intensities ranging between 111 and $113 \mathrm{~dB}(\mathrm{~A})$. The vibration measurements as root mean square value in metres per second per second $\left(\mathrm{rms}\right.$ in $\left.\mathrm{m} / \mathrm{s}^{2}\right)$ were made with a Brüel and Kjaer triaxial accelerometer mounted rigidly on the vibrating surface. The signals from the accelerometer were then amplified and taperecorded. The recorded signals were finally analysed into octave band levels in the frequency range between 4 and $2000 \mathrm{~Hz}$.

The hand-arm vibration exposure limits recently proposed in the Draft for Development DD43 (British Standards Institution, 1975) can be extrapolated into two curves (400-minute and 150minute lines). The standard suggests that any vibration spectrum which lies entirely below the 400-minute line can be considered safe. Any spectrum which exceeds the 150-minute curve in any octave band is considered unacceptable for regularly repeated daily exposure. For exposure periods of 150-400 minutes/day, it is suggested that an interpolation between the two curves is made (Hempstock and O'Connor, 1975).

In our series the vibration spectra of the rockdrills are shown in Figures 1-4. The levels in almost all the measurements exceed the 150-minute line as well as the line proposed by the International Standards Organisation (ISO) in octave bands mainly centred on $31.5 \mathrm{~Hz}$. There was no marked difference between the two drills but, in general, the levels measured on the Ingersoll drill appeared to be marginally higher than those on the Holman, especially during the withdrawal stage of the drilling operation. 


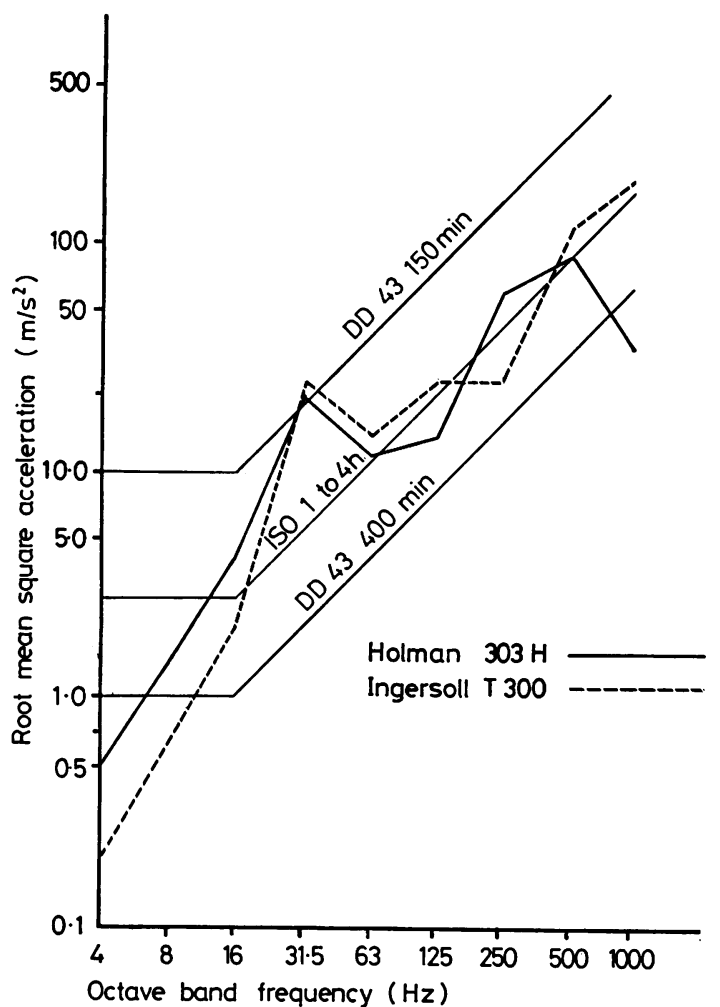

Fig. 1 Vibration levels measured radial to drill bit.

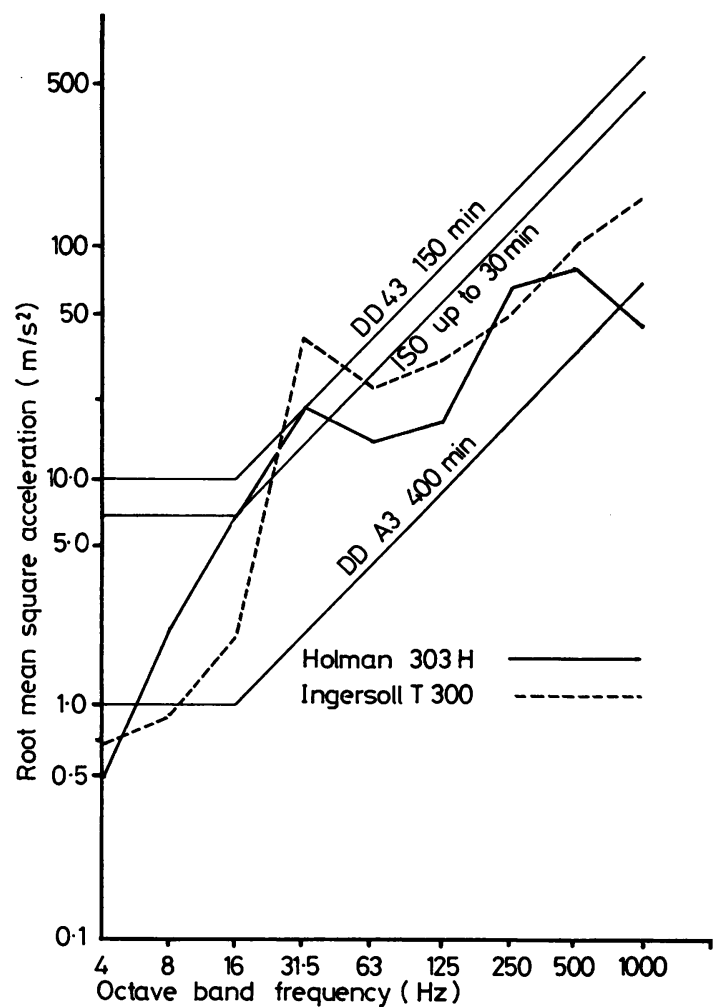

Fig. 2 Vibration levels measured radial to drill bit; drill being withdrawn.

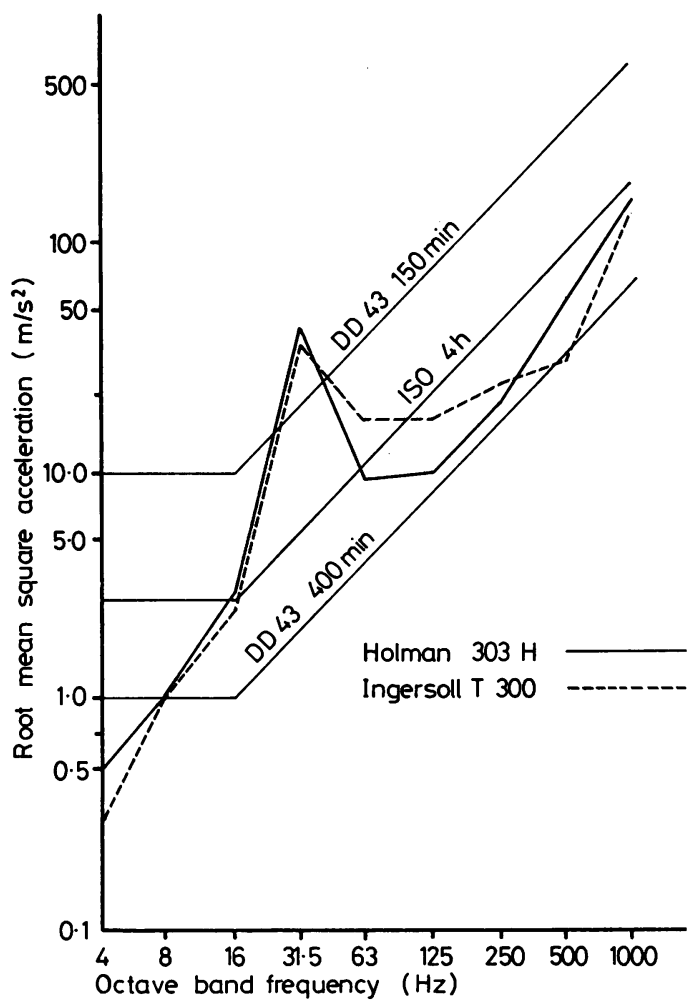

Fig. 3 Vibration levels measured parallel to drill bit.

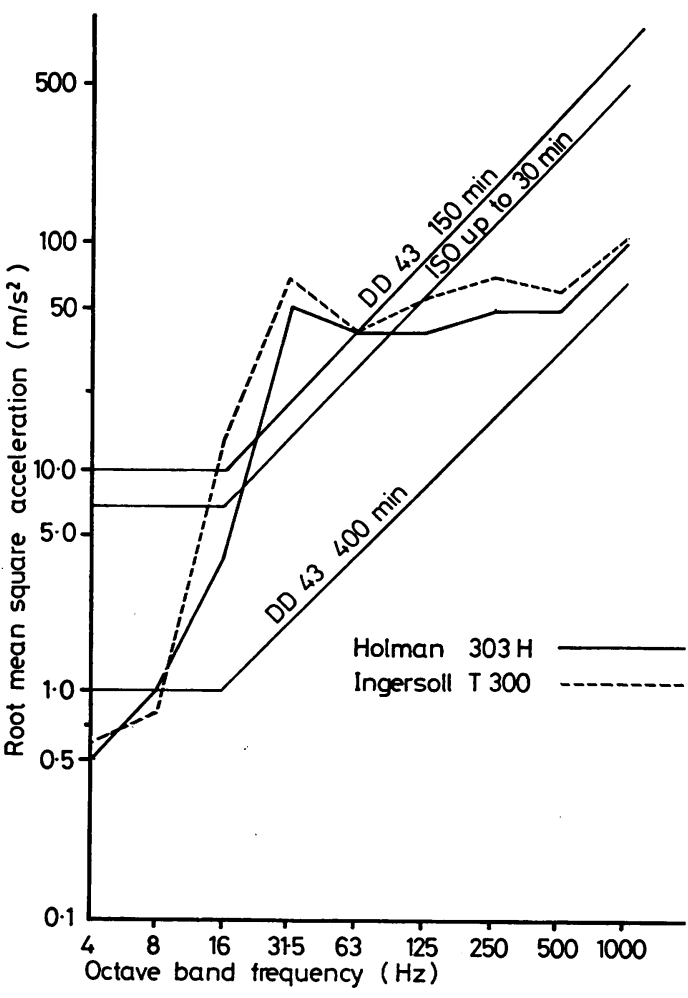

Fig. 4 Vibration levels measured parallel to drill bit; drill being withdrawn. 


\section{Materials and methods}

\section{POPULATIONS STUDIED}

Only those miners who regularly used the rock-drills in the fluorspar mines, or who had moved from other mines using similar rock-drills, were included in the vibration group. The control group comprised workers who had never used vibrating tools.

The criteria for exclusion from the study were:-

1. history of CWF;

2. history of secondary causes of Raynaud's phenomenon other than vibration;

3. history of more than one laceration or fracture in the hands or digits, or severe or complicated injury involving nerve or blood vessels or history of some significant operation such as sympathectomy, laminectomy, excision of cervical ribs, scalenectomy;

4. history of exposure to vibration from tools other than rock-drills, such as chainsaws, grinders or fettling instruments.

These criteria were based on the fact that they could give rise to symptoms of Raynaud's phenomenon and might thereby mask the prevalence of VWF resulting from the specific use of the rockdrills.

Participation in the study was purely voluntary, and out of the total workforce of 150 men, which included 60 rock-drillers and 90 other mine workers, 115 men $(77 \%)$ agreed to take part. These 115 men comprised 56 rock-drillers and 59 other workers. The 35 men who did not respond to the survey comprised four drillers and 31 others, showing that the response rate for the drillers was 56 out of 60 $(93 \%)$ in comparison to 59 of the 90 other workers $(65 \%)$. However, as the main aim was to study the prevalence of VWF among the rockdrillers, the relatively poor response from the non-vibration group was thought to be unimportant.

Of the 115 men participating in the survey, 20 with a history of working with vibratory tools other than rock-drills in their previous occupations were excluded from further evaluation. Four men in this group also had significant medical abnormalities. In addition, six men were rejected solely for medical reasons (criteria 1, 2 and 3) thus leaving 89 men (45 in the control and 44 in the vibration group) for further study. Subsequently, five subjects (three in the control and two in the vibration group) who were found to be suffering from CWF were excluded from further analysis. CWF was diagnosed when no other predisposing cause could be found and the symptoms of intermittent blanching of fingers were not related to the exposure to vibration; the overall prevalence was $5.6 \%$. In total, therefore, 31 men were rejected leaving 84 men of which 42 were in the control or non-vibration group and 42 (representing about $70 \%$ of the total vibration-exposed population) in the vibration group for final analysis.

Although the two final groups (control and vibration) were as 'pure' as possible, in some cases the exposure to vibration was measured as the summation of separate, and not necessarily the consecutive, exposures of an individual in different mines or in the same mine.

\section{METHODS}

The survey was carried out in three stages. Initially each subject was asked to fill up a questionnaire which chiefly comprised personal, medical and occupational histories of the individual, and subjective descriptions of the white finger and its associated symptoms. At the second stage, each man was interviewed by one of the medical investigators to check the answers he had given and to correct any apparent inconsistencies. Finally, the clinical examinations were carried out blindly, without any reference to the questionnaire; this was completed between 13-17 September 1976. To minimise errors from different observers, the general medical examination was carried out by one medical investigator (DSC) and the local and neurological examinations of the hands were carried out by another (WT). The general medical examinations included height. weight, radial pulse, blood pressure and examination of the heart, lungs, abdomen, central nervous system, extremities and joints. For the measurement of blood pressure the first audible heart sound was recorded as systolic and the point when it became inaudible as diastolic; the upper limit of normal was taken as $140 / 90 \mathrm{mmHg}$. The other tests included the following:

\section{Finger circumference test}

The right and left index fingers were measured at, above and below the proximal interphalangeal joint, and the mean of these three was taken as the finger circumference.

\section{Sensory function tests}

Tests for light touch, pressure touch, superficial pain, pressure pain, sense of shape and stereognosis were carried out according to Hutchinson's Clinical Methods (1973), including light touch by a wisp of cotton wool, pressure touch by the blunt end of a pencil, superficial pain by a pin-prick, pressure pain by squeezing soft tissues of hand and fingers, sense of shape by placing new $1 p$ and $50 p$ coins on the palmar surface of the left and right hands, and stereognosis by passively moving the fingers in different directions. 
Somatic space-sense tests

The two-point discrimination (TPD) and the depthsense aesthesiometer or ridge tests were carried out with the instruments designed by Renfrew (1969). A specially designed electronic thermometer was used to ensure that, before testing, the temperature of the palms and digits exceeded $25^{\circ} \mathrm{C}$.

For the TPD test the instrument had two sharp ridges which joined at one end and separated gradually at the other. The subject's index fingers, midway between the whorl and the nail, were placed at the common junction of two ridges and the instrument was moved lengthwise underneath the finger tip. The minimum distance between the two ridges at which the subject first recognised the sensation of a double tactile stimulation was taken as the threshold of tactile discrimination and measured to $0.1 \mathrm{~mm}$. The upper limit of normal was regarded as $0.4 \mathrm{~mm}$.

For the ridge test, the instrument consisted of a vertical ridge which disappeared into the plane at one point and increased gradually to a depth of $1 \mathrm{~mm}$ at the other. The examiner slowly moved the instrument lengthwise across the subject's index finger tip as in the TPD, the point at which the patient felt a distinct ridge being regarded as the threshold for depth-sense. The upper limit of normal was taken to be $0.25 \mathrm{~mm}$ (Taylor and Pelmear, 1975).

For administrative reasons the underground workers were examined in their off-periods away from the mines, but most of the surface workers were examined during their normal working hours. However, further analysis of occupational history showed that almost $50 \%$ of the underground workers belonged to the control group. The possible element of bias due to two separate procedures for examinations may not, therefore, be as significant as it appears to be. Subsequently, the stage assessments of VWF were carried out by the two medical investigators (DSC and WT) acting independently and on the principles described by Taylor and Pelmear (1975). The stages are as follows:-

Stage $0 \quad$ : no symptoms;

Stage $0_{T} / 0_{N} \quad$ : intermittent tingling or numbness but no interference with work, domestic or social activities;

Stage 1 : blanching of one or more finger tips without any interference with work, domestic or social activities;

Stage 2 : blanching characterised by increased frequency and number of fingers affected, usually triggered by cold. There is slight interference with domestic and social activities but not with work;
Stage 3 : extensive blanching with frequent episodes in summer as well as in winter. There is definite interference with work, domestic and social activities;

Stage 4 : extensive blanching affecting all digits both in summer as well as in winter, leading to a change of occupation.

The men in the intermediate stage of $0_{\mathrm{T}} / 0_{\mathrm{N}}$ were not considered to have reached the white finger stage. They were, therefore, included in Stage 0 for further analysis and referred to as Stage $0^{+}$(i.e. Stage $0+$ Stage $0_{\mathrm{T}} / 0_{\mathrm{N}}$ ).

\section{Results}

The analyses were carried out on the 42 control and 42 vibration-exposed subjects after the exclusion of five men suffering from CWF.

\section{EPIDEMIOLOGY}

\section{Population distribution}

It was evident from the data shown in Table 1 that the proportion of men in the control and the vibration groups in the four mines was very variable and the difference was statistically significant $\left(\chi^{2}=10.2(3\right.$ d.f.); $P<0.025)$. This was largely a reflection of the different activities in the four mines.

The prevalence of vibration-induced white finger

The prevalence of VWF was defined as the percentage of Stages 1, 2 and 3 in the vibration group. Of the 42 men in the vibration group, 21 were in Stage $0^{+}$(including three in Stage $0_{\mathrm{T}} / 0_{\mathrm{N}}$ ), none were in Stage 1, five men (11.9\%) were in Stage 2 and $16(38.1 \%)$ were in Stage 3 of VWF. Two features stand out from Tables 1 and 2 ; there were no men at Stage 1, and the prevalence of VWF varied greatly between the four mines $(19-93 \% ; P<0.001)$ with an overall rate of $50 \%$.

In Figure 5 the prevalence of VWF in the vibration group at each of the four mines is plotted against the median exposure time, and in Figure 6 the prevalence is plotted against the mean exposure time. The median was thought to be a better indication of average exposure than the arithmetic mean, as Groverake mine, for example, had 13 men with exposures of 10 years or less together with three men who had used a rock-drill for over 20 years. Further stratification of the exposure time showed that six men had interruptions ranging from six months to 13 years; of these, four men had one interruption, one man had two and the other had three interruptions. Of these six men, only one belonged to Stage 0 VWF 
Table 1 Population studied, prevalence of VWF, latent period, exposure time and age of workers in four different mines

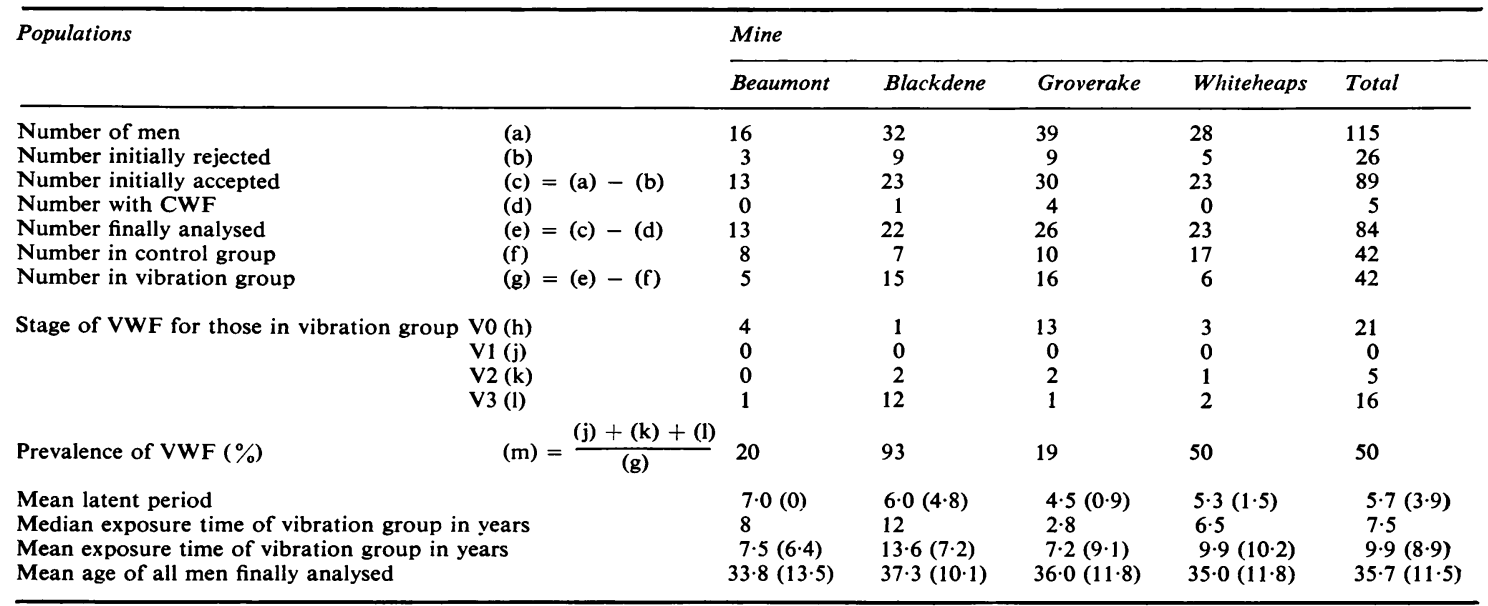

Numbers in parentheses denote the estimated standard deviation of a single observation.

Table 2 Number of men, age, exposure time and latent period by stage of $V W F$

\begin{tabular}{|c|c|c|c|c|}
\hline \multirow[t]{2}{*}{ Variables } & \multicolumn{3}{|l|}{ Stage of $V W F$} & \multirow[t]{2}{*}{ Total } \\
\hline & $V O+$ & $V 2$ & $V 3$ & \\
\hline $\begin{array}{l}\text { Number of men } \\
\text { Mean age } \\
\text { Median exposure time (years) } \\
\text { Mean exposure time (years) } \\
\text { Median latent period (years) } \\
\text { Mean latent period (years) }\end{array}$ & $\begin{array}{l}21 \\
31 \cdot 7(10 \cdot 0) \\
2 \cdot 0 \\
5 \cdot 1(7 \cdot 6) \\
\text { Not applicable } \\
\text { Not applicable }\end{array}$ & $\begin{array}{l}5 \\
31 \cdot 2(8 \cdot 1) \\
6 \cdot 0 \\
8 \cdot 5(7 \cdot 3) \\
4 \cdot 0 \\
2 \cdot 9(1 \cdot 5)\end{array}$ & $\begin{array}{l}16 \\
39 \cdot 8(7 \cdot 2) \\
16 \cdot 5 \\
16 \cdot 6(7 \cdot 0) \\
6 \cdot 3 \\
6 \cdot 6(4 \cdot 1)\end{array}$ & $\begin{array}{l}42 \\
34 \cdot 7(9 \cdot 5) \\
7 \cdot 5 \\
9 \cdot 9(8 \cdot 9) \\
5 \cdot 0 \\
5 \cdot 7(3 \cdot 9)\end{array}$ \\
\hline
\end{tabular}

Numbers in parentheses denote the estimated standard deviation of a single observation.

whereas the other five men were at Stage 3. The man in Stage 0 had a total exposure of two years and the mean exposure time of the five men in Stage 3 was $13 \cdot 8$ years (SD 4.6). Considering both the continuous and interrupted exposure to vibration, Figures 5 and 6 suggest that the difference in prevalence of VWF in the four mines could be explained by differences in exposure time, longer exposure leading to a high prevalence of VWF. It was considered to be reasonable to combine the results for the four mines in any further analysis, especially in view of the small number of men in individual mines.

\section{Age distribution}

The ages of the men ranged from 17 to 62 years (Tables 1 and 2). The difference in mean age of the control and vibration groups was not significant. However, the mean age for the various stages of VWF differed significantly $(P<0.05)$, that for Stage 3 being the highest, reflecting the association of exposure time with the stage of VWF.

\section{Latent period}

The latent period (Tables 1 and 2) defined as the time interval between the beginning of exposure to

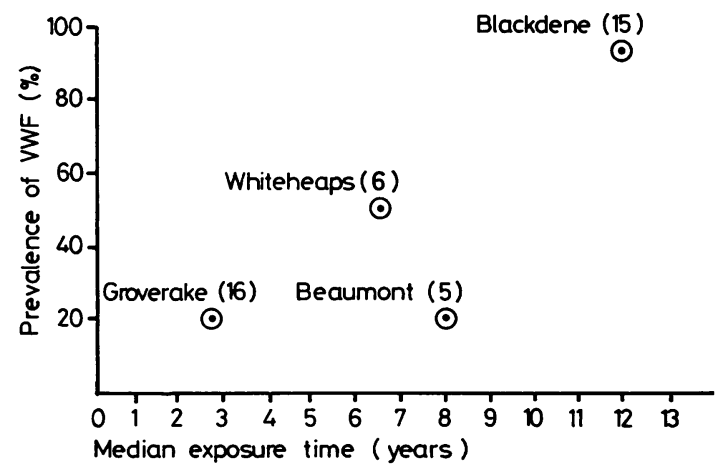

Fig. 5 Prevalence of VWF against median exposure time for the four mines. (Numbers in parentheses are numbers of men in the vibration group, for each mine). 


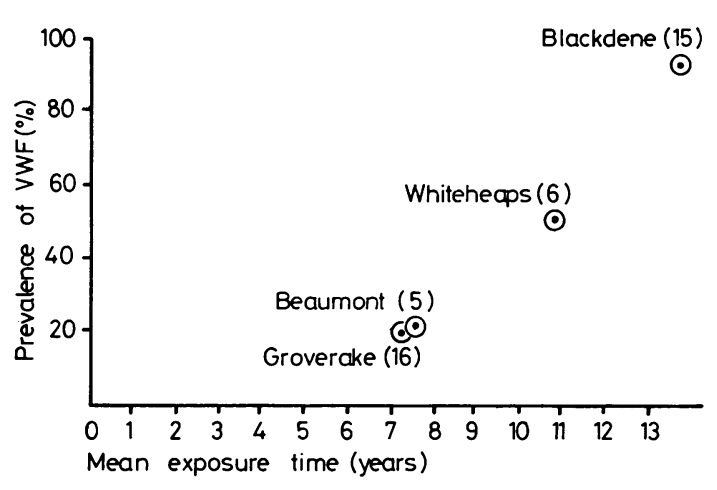

Fig. 6 Prevalence of VWF against mean exposure time for the four mines. (Numbers in parentheses are numbers of men in the vibration group, for each mine).

vibration and the appearance of the first white finger tip, ranged from 1 to 19 years with a mean of $5 \cdot 7$ years. The mean latent period for men with Stage 2 VWF $(2.9$ years) differed significantly at the $5 \%$ level from the mean latent period for men with Stage 3 VWF (6.6 years).

$V W F$, smoking and drinking habits

Table 3 shows that the proportion of smokers, exsmokers and non-smokers in the control and vibration groups differed significantly $\left(\chi^{2}=12 \cdot 3\right.$ ( 2 d.f.); $P<0.01)$. This was because there were fewer smokers in the vibration than in the control group. However, the difference in smoking habits of the men in different stages of VWF was not significant. Although 36 men $(85.7 \%)$ in the control group and $41(97.6 \%)$ in the vibration group stated that they consumed alcohol regularly, the difference was not statistically significant $(P=0 \cdot 11)$.

\section{Associated symptoms and interference with domestic and social activities}

In the questionnaire the men were asked whether they were suffering from pain in any part of the upper limb from the hands to the shoulders, and if there was any interference with fine work or hobbies. The results (Table 4) showed that in Stage 3 of VWF all men had some form of hand-arm syndrome and interference with hobbies and 12 out of 16 $(75 \%)$ had interference with fine work.

\section{Frequency of attacks of VWF}

The analysis in Table 5 shows that the attacks of VWF were significantly more frequent among the men in Stage 3 than those in Stage 2, in both summer and winter $(P<0.05)$.

\section{Fingers affected}

The fingers in both hands were affected almost equally (Table 6). In Stage 3, the index, middle and ring fingers were involved in both hands and, in general, the little fingers and thumbs were the last to be affected. About $44 \%$ of the left and $38 \%$ of the right thumbs were affected in Stage 3, and $20 \%$ of the thumbs on each hand were affected in Stage 2.

\section{CLINICAL FEATURES}

The general medical examinations did not indicate any abnormality in the vibration-exposed group, and there was no significant difference between this group and the controls. The specific features of the hands were as follows:-

\section{Dominant hand and index finger circumference}

The results of these two measurements were considered together as they were found to be closely interrelated. There were significantly $(P=0.04)$ more left-handed subjects in the control group (11, as opposed to three in the vibration group) but otherwise the mean finger circumference was similar in both groups.

Appearance of hands and digits

Clinical inspection confirmed subjective description of digital blanching in all 21 of the 42 vibrationexposed men. This verification was facilitated by the low temperatures occurring on the September evenings when the clinical examinations took place; white finger is aggravated by cold conditions.

\section{Routine sensory tests}

In the vibration group, $21 \%-60 \%$ of men reacted abnormally to various tests. The percentage of the abnormals increased progressively from Stage 0 to Stage 3 VWF. None of the controls showed an abnormal response to any of the touch, pain, shape and stereognosis tests, although some had an abnormal response to the TPD and ridge tests. For all the tests, the difference in the proportion of abnormal responses in the control and vibration groups was highly significant $(P<0.01$ for shape and stereognosis and $P<0.001$ for the other tests).

Table 7 suggests that the majority of men having an abnormal response are abnormal in both hands. Therefore, for simplicity of description of the results, henceforth a man has been considered to have an abnormal response to a test if either of his hands is abnormal.

Touch. Of the $\mathbf{4 2}$ men in the vibration group, 17 $(40 \%)$ had abnormal sensitivity to the light touch test. Three men $(14 \%)$ in Stage $0^{+}$, one man $(20 \%)$ 
Table 3 Smoking and drinking habits of population studied

\begin{tabular}{|c|c|c|c|c|c|c|}
\hline \multirow[t]{2}{*}{ Groups } & \multirow[t]{2}{*}{ Total control group } & \multicolumn{3}{|c|}{ Vibration group } & \multirow[t]{2}{*}{ Total vibration group } & \multirow[t]{2}{*}{ Total population } \\
\hline & & Stage 0 & Stage 2 & Stage 3 & & \\
\hline $\begin{array}{l}\text { Smoker } \\
\text { Ex-smoker } \\
\text { Non-smoker } \\
\text { Not answered } \\
\text { Total }\end{array}$ & $\begin{array}{r}33 \\
3 \\
3 \\
3 \\
42\end{array}$ & $\begin{array}{r}9 \\
3 \\
9 \\
21\end{array}$ & $\begin{array}{l}3 \\
2 \\
0 \\
5\end{array}$ & $\begin{array}{r}8 \\
4 \\
4 \\
16\end{array}$ & $\begin{array}{r}20 \\
9 \\
13 \\
0 \\
42\end{array}$ & $\begin{array}{r}53 \\
12 \\
16 \\
3 \\
84\end{array}$ \\
\hline $\begin{array}{l}\text { Alcohol drinker } \\
\text { Non-drinker } \\
\text { Total }\end{array}$ & $\begin{array}{r}36 \\
6 \\
42\end{array}$ & $\frac{21}{21}$ & $\frac{5}{5}$ & $\begin{array}{r}15 \\
1 \\
16\end{array}$ & $\begin{array}{r}41 \\
1 \\
42\end{array}$ & $\begin{array}{r}77 \\
7 \\
84\end{array}$ \\
\hline
\end{tabular}

Table 4 Number of workers complaining of associated symptoms and interference with fine work and hobbies

\begin{tabular}{|c|c|c|c|c|c|}
\hline \multirow[t]{2}{*}{ Handicap } & \multirow[t]{2}{*}{ Total control group } & \multicolumn{3}{|c|}{ Vibration group } & \multirow[t]{2}{*}{ Total } \\
\hline & & Stage 0 & Stage 2 & Stage 3 & \\
\hline \multicolumn{6}{|l|}{ Associated symptoms } \\
\hline Tingling in hands & $2(41)$ & $5(20)$ & $5(5)$ & $15(16)$ & $27(82)$ \\
\hline Numbness in hands & $2(41)$ & $4(19)$ & $5(5)$ & $16(16)$ & $27(81)$ \\
\hline Pain in fingers & $1(41)$ & $3(18)$ & $1(4)$ & $13(15)$ & $18(78)$ \\
\hline Pain in wrists & $2(41)$ & $3(17)$ & $2(5)$ & $6(16)$ & $13(79)$ \\
\hline Pain in elbows & $3(41)$ & $0(17)$ & $1(5)$ & 3 (15) & 7 (78) \\
\hline Pain in shoulders & $3(41)$ & $4(18)$ & $1(5)$ & $7(16)$ & $15(80)$ \\
\hline 'Yes' to any of the above & $6(42)$ & $10(21)$ & $5(5)$ & $16(16)$ & $37(84)$ \\
\hline \multicolumn{6}{|l|}{ Interference with fine work } \\
\hline Fine work & $1(42)$ & $0(19)$ & $1(5)$ & $9(14)$ & $11(80)$ \\
\hline Fastening buttons & $0(42)$ & 0 (19) & $0(5)$ & $8(14)$ & $8(80)$ \\
\hline Handling small objects & $1(42)$ & $0(19)$ & $1(5)$ & 7 (14) & $8(80)$ \\
\hline Distinguishing hot and cold & $0(42)$ & 1 (19) & $0(5)$ & $6(14)$ & $8(80)$ \\
\hline 'Yes' to any of the above & $2(42)$ & $1(18)$ & $1(5)$ & $12(16)$ & $16(84)$ \\
\hline \multicolumn{6}{|l|}{ Interference with hobbies } \\
\hline Swimming & $1(40)$ & $1(21)$ & $3(4)$ & $9(11)$ & $14(76)$ \\
\hline Gardening & 0 (39) & $0(20)$ & $1(3)$ & $11(14)$ & $12(76)$ \\
\hline Washing car & $0(39)$ & $0(20)$ & $4(5)$ & $10(11)$ & $14(75)$ \\
\hline Fishing & $0(39)$ & $0(19)$ & $0(2)$ & $8(8)$ & $8(65)$ \\
\hline Outdoor activities & $0(39)$ & $0(19)$ & $4(5)$ & $12(14)$ & $16(77)$ \\
\hline Playing games & $0(38)$ & $0(21)$ & $0(3)$ & $7(8)$ & $7(70)$ \\
\hline Other hobbies & $1(20)$ & $0(17)$ & 1 (4) & $14(14)$ & $16(55)$ \\
\hline 'Yes' to any of the above & $2(42)$ & $1(21)$ & $4(5)$ & $16(16)$ & $21(42)$ \\
\hline
\end{tabular}

Numbers in parentheses are the number of people who filled in the questionnaire.

Table 5 Frequency of attacks of VWF according to season

\begin{tabular}{|c|c|c|c|c|}
\hline \multirow[t]{2}{*}{ Freạency } & \multicolumn{2}{|l|}{ Winter } & \multicolumn{2}{|l|}{ Summer } \\
\hline & Stage 2 & Stage 3 & Stage 2 & Stage 3 \\
\hline $\begin{array}{l}\text { Never } \\
<1 / \text { month } \\
1-3 / \text { month } \\
1-4 / \text { month } \\
5+/ \text { month } \\
\text { Total } \\
\text { Significance of difference in proportion of attacks }>3 \\
\quad \text { times/month between Stages } 2 \text { and } 3 \text { using Fisher's Exact } \\
\text { Test }\end{array}$ & $\left.\begin{array}{l}0 \\
1 \\
1 \\
2 \\
1\end{array}\right\} \begin{array}{l}2 \\
3 \\
5\end{array}$ & $\left.\begin{array}{l}0 \\
0 \\
0 \\
9 \\
7\end{array}\right\} \begin{array}{l}0 \\
16 \\
16\end{array}$ & $\left.\begin{array}{l}1 \\
3 \\
1 \\
0 \\
0\end{array}\right\} \begin{array}{l}5 \\
5 \\
5\end{array}$ & $\left.\begin{array}{l}1 \\
5 \\
1 \\
8 \\
1\end{array}\right\} \begin{array}{r}7 \\
9 \\
16\end{array}$ \\
\hline
\end{tabular}

in Stage 2 and 13 men $(81 \%)$ in Stage 3 were abnormal.

For the pressure touch test, 13 men $(31 \%)$ in the vibration group were abnormal. These comprised one man $(5 \%)$ in Stage $0^{+}$, one man $(20 \%)$ in Stage 2 and 11 men $(69 \%)$ in Stage 3.

Pain. The pin-prick test was abnormal in 17 of the 
Table 6 Fingers affected in VWF

\begin{tabular}{llllll}
\hline Finger & \multicolumn{2}{l}{ Left hand } & \multicolumn{3}{l}{ Right hand } \\
\cline { 2 - 3 } \cline { 5 - 6 } \cline { 5 - 6 } & Stage 2 (5) & Stage 3 (16) & & Stage 2 (5) & Stage 3 (16) \\
\hline Index & 4 & 16 & 5 & 16 \\
Middle & 4 & 16 & 5 & 16 \\
Ring & 4 & 16 & 3 & 16 \\
Little & 3 & 12 & 2 & 12 \\
Thumb & 1 & 7 & 1 & 6 \\
\hline
\end{tabular}

42 men $(40 \%)$ in the vibration group: these comprised two men $(10 \%)$ in Stage $0^{+}$, four men $(80 \%)$ in Stage 2 and 11 men $(69 \%)$ in Stage 3.

The pressure pain test elicited an abnormal response in one man $(5 \%)$ in Stage $0^{+}$, three men $(60 \%)$ in Stage 2 and nine men $(56 \%)$ in Stage 3. In all, 13 men $(31 \%)$ in the vibration group were abnormal.

Sense of shape and stereognosis. For this combination of tests nine men $(21 \%)$ in the vibration group were abnormal. These comprised one man $(5 \%)$ in Stage $0^{+}$, none in Stage 2 and eight men $(50 \%)$ in Stage 3.

Two-point discrimination and ridge test. In the TPD test an abnormal response was found in 20 men
$(48 \%)$ in the vibration group. Four men $(19 \%)$ in Stage $0^{+}$, three men $(60 \%)$ in Stage 2 and 13 men $(81 \%)$ in Stage 3 were abnormal. In addition, five of the 41 men (12\%) examined in the control group were abnormal.

The ridge test was abnormal in $25(60 \%)$ of the vibration group; these comprised six men $(29 \%)$ in Stage $0^{+}$, four men $(80 \%)$ in Stage 2 and 15 men $(94 \%)$ in Stage 3 . However, among the control group, of which only $\mathbf{4 1}$ men were examined, four $(10 \%)$ had an abnormal response to the ridge test.

\section{Discussion}

The results of the survey showed the extent and the pattern of VWF prevailing among the rock-drillers.

Figures 5 and 6 strongly suggest that the prevalence of VWF is related to exposure time. The analysis of the exposure time of five men in Stage 3 with interrupted exposures showed that the arithmetic mean of their accumulated exposure (13.8 years) was not greater than that found in all the $\mathbf{1 6}$ men $(16.6$ years) in Stage 3 . In our opinion the results strengthened the argument for the cumulative theory of VWF: all but one man with interrupted exposures belonged to Stage 3, which has been described as irreversible and progressive by Taylor

Table 7 Number of men, in different groups, with abnormal responses to various clinical tests

\begin{tabular}{|c|c|c|c|c|c|c|c|}
\hline Tests & & $\begin{array}{l}\text { Control } \\
\text { total }\end{array}$ & Stage $0^{+}$ & Stage 2 & Stage 3 & $\begin{array}{l}\text { Vibration } \\
\text { total }\end{array}$ & $\begin{array}{l}\text { Significance test } \\
\text { Control : vibration }\end{array}$ \\
\hline No. of men in group & & 42 & 21 & 5 & 16 & 42 & \\
\hline Light touch & $\begin{array}{l}\text { Left hand } \\
\text { Right hand } \\
\text { Either hand }\end{array}$ & $\begin{array}{l}\mathbf{0} \\
0 \\
0\end{array}$ & $\begin{array}{l}3 \\
2 \\
3\end{array}$ & $\begin{array}{l}1 \\
1 \\
1\end{array}$ & $\begin{array}{l}12 \\
13 \\
13\end{array}$ & $\begin{array}{l}16 \\
16 \\
17\end{array}$ & $* * *$ \\
\hline Pressure touch & $\begin{array}{l}\text { Left hand } \\
\text { Right hand } \\
\text { Either hand }\end{array}$ & $\begin{array}{l}0 \\
0 \\
0\end{array}$ & $\begin{array}{l}1 \\
1 \\
1\end{array}$ & $\begin{array}{l}1 \\
1 \\
1\end{array}$ & $\begin{array}{l}10 \\
11 \\
11\end{array}$ & $\begin{array}{l}12 \\
13 \\
13\end{array}$ & $* * *$ \\
\hline Superficial pain & $\begin{array}{l}\text { Left hand } \\
\text { Right hand } \\
\text { Either hand }\end{array}$ & $\begin{array}{l}\mathbf{0} \\
0 \\
\mathbf{0}\end{array}$ & $\begin{array}{l}2 \\
1 \\
2\end{array}$ & $\begin{array}{l}4 \\
4 \\
4\end{array}$ & $\begin{array}{r}9 \\
11 \\
11\end{array}$ & $\begin{array}{l}15 \\
16 \\
17\end{array}$ & $* * *$ \\
\hline Pressure pain & $\begin{array}{l}\text { Left hand } \\
\text { Right hand } \\
\text { Either hand }\end{array}$ & $\begin{array}{l}0 \\
0 \\
0\end{array}$ & $\begin{array}{l}1 \\
1 \\
1\end{array}$ & $\begin{array}{l}3 \\
2 \\
3\end{array}$ & $\begin{array}{l}8 \\
9 \\
9\end{array}$ & $\begin{array}{l}12 \\
12 \\
13\end{array}$ & $* * *$ \\
\hline Sense of shape and position (stereognosis) & $\begin{array}{l}\text { Left hand } \\
\text { Right hand } \\
\text { Either hand }\end{array}$ & $\begin{array}{l}0 \\
0 \\
0\end{array}$ & $\begin{array}{l}1 \\
1 \\
1\end{array}$ & $\begin{array}{l}0 \\
0 \\
0\end{array}$ & $\begin{array}{l}8 \\
7 \\
8\end{array}$ & $\begin{array}{l}9 \\
8 \\
9\end{array}$ & $* *$ \\
\hline TPD test & $\begin{array}{l}\text { Left hand } \\
\text { Right hand } \\
\text { Either hand }\end{array}$ & $\begin{array}{r}4 \\
+\dagger \quad 4 \\
5\end{array}$ & $\begin{array}{l}4 \\
4 \\
4\end{array}$ & $\begin{array}{l}2 \\
3 \\
3\end{array}$ & $\begin{array}{l}13 \\
13 \\
13\end{array}$ & $\begin{array}{l}19 \\
20 \\
20\end{array}$ & $* * *$ \\
\hline Ridge test & $\begin{array}{l}\text { Left hand } \\
\text { Right hand } \\
\text { Either hand }\end{array}$ & $\begin{array}{r}3 \\
++\begin{array}{l}3 \\
4\end{array}\end{array}$ & $\begin{array}{l}6 \\
6 \\
6\end{array}$ & $\begin{array}{l}4 \\
4 \\
4\end{array}$ & $\begin{array}{l}15 \\
15 \\
15\end{array}$ & $\begin{array}{l}25 \\
25 \\
25\end{array}$ & $* * *$ \\
\hline
\end{tabular}

${ }^{* * *} ; P=0.001$ (very highly significant): ${ }^{* *} ; P=0.01$ (highly significant): $\dagger$; only 40 men were examined: $\dagger \dagger$; only 41 men were examined. The number of men with both hands showing an abnormal response can be obtained as the number with the left hand abnormal plus the number with the right hand abnormal minus the number with either hand abnormal. 
and Pelmear (1975). A similar relationship with exposure time was shown by St Clair Renard (Lidström, 1974) in his study of circulation disorders among rock-drill operators at Malmberget in the north of Sweden, where $52 \%$ of the men who had worked with rock-drills for 1-5 years reported recurrent attacks of vasospasm; the corresponding figure for men who had been exposed for more than five years was $70 \%$. Taylor and Pelmear (1975) made similar observations on chain-saw operators, showing a VWF prevalence of $85 \%$ in 1970 and $87 \%$ in 1972 . However, in the same study the prevalence of VWF among pedestal grinders was only $22 \%$ in 1971 compared with $96 \%$ in the January 1970 survey; this was attributable to an intake of new grinders, diluting the population. In the present survey, a similar observation on the effect of dilution of the work-force was made in Groverake mine, which has a relatively rapid turnover of workers in contrast to the stable population at the Blackdene mine. However, other factors such as the geological variation (hardness of rocks in different strata) and the vibration characteristics of the different drills, especially between $31.5 \mathrm{~Hz}$ and $125 \mathrm{~Hz}$, could also have influenced the variations between the mines. Not enough men were involved to investigate these possibilities. Seyring (1930) observed that, out of 189 cast-iron fettlers in a large metallurgical works, of those who had been working for three or more years, 61 out of 72 working on hard material had VWF, whereas only 16 out of 31 working on soft material developed this syndrome. This suggests that the hardness of the material is an important factor in the aetiology of VWF.

\section{LATENT PERIOD}

According to the definition, the latent period is the time interval between Stage 0 and Stage 1 of VWF and it is regarded as a better indicator of risk than the prevalence rate (Taylor and Pelmear, 1975). As there was not a single case of Stage 1, the assessments in our survey were retrospective and therefore subjective. In order to estimate the latent period more accurately it would be better to have a prospective study with periodic examination of the rockdrillers, using clinical tests related to blood flow and sensory loss in the digits.

\section{ASSOCIATED SYMPTOMS AND SOCIAL}

\section{HANDICAPS}

Of the 42 vibration-exposed subjects 31 ( $73 \%$ ) complained of some form of hand-arm syndrome (Table 4); this compared highly unfavourably with the mean figure of $12 \%$ found by Taylor and Pelmear (1975) among the saw-users, pedestal grinders and chippers.
This was probably caused by the larger size and heavier weight of the rock-drills.

\section{CHANGES IN HANDS}

In our series of cases the digits of both hands appeared to be affected equally (Table 6) whereas Hunter et al. (1945) observed that the left hand was the one usually affected. In 161 of their VWF cases among 286 rivetters, caulkers, fettlers, scalers, drillers and grinders, 76 workers $(47 \cdot 2 \%)$ had the left hand affected, 32 workers $(19.8 \%)$ had the right hand affected, but in 53 subjects only $(32.9 \%)$ were both hands involved. The discrepancy in our study was attributable to the miners using both hands simultaneously, usually with the left hand on the handle of the drill and the right hand on the control valve which determines the pressure needed for drilling.

The finger circumference measurements were not significantly different between the groups, in contrast to the results of the earlier study carried out by Taylor and Pelmear (1975) which had shown that, in general, the vibration-exposed subjects had larger fingers and joints than the controls. This could possibly be because, in our study, the majority of the men in the control group were selected from the manual workforce and not from any sedentary occupational group.

Of the neurological tests (Table 7) the light touch, TPD and the ridge test were useful, especially in the diagnosis of Stage 3 of VWF, the ridge test being the most sensitive. This observed sensitivity of the ridge test supports the findings of Taylor and Pelmear (1975) in the survey of chain-saw operators and the pedestal grinders. More recently, using a Von Frei's aesthesiometer, Crosetti et al. (1976) found that in the vibration-exposed subjects the threshold of tactile stimulation was significantly higher (at the $1 \%$ level) not only on the palmar surface of the hands and the digits, but also on the dorsal surface of the fingers and on both sides of the thenar and hypothenar eminences of the hands. Further work is therefore necessary to elucidate whether the sensory changes may extend beyond the digits.

In spite of the small number and limited exposure of workers studied, this survey confirms that VWF can be found in rock-drillers in fluorspar mines. The results suggest that, to minimise the risk, the vibration levels of the drills currently used in the mines should be reduced below the proposed damage level criteria. The clinical tests show that the ridge test is one of the most sensitive tests available at present; they also indicate the relative usefulness of the TPD and the light touch tests in the diagnosis of VWF. At the same time the results show that not one 
of these tests can be used alone as a single objective test. Both the epidemiological and clinical studies show the bilateral pattern of VWF and support the views of McCallum (1971) that VWF has to be considered more seriously than in the past, especially in relation to the quality of life outside working hours, and to the effects of VWF on hobbies or other recreation.

We wish to thank Dr R. I. McCallum, Department of Occupational Health and Hygiene, University of Newcastle upon Tyne, for his valuable help and advice throughout this survey, and Dr Ian Hempstock and Mr David O'Connor, Department of Applied Physics, University of Salford, for the measurement of vibration in rock drills. We are grateful to the British Steel Corporation and especially to Dr D. M. Fanning, Chief Medical Officer, for permission to publish the VWF data.

\section{References}

British Standards Institution (1975). Guide to the Evaluation of Exposure of the Human Hand-arm System to Vibration. Draft for Development DD43. BSI : London.

Crosetti, L., Casalone, E., and Meda, E. (1974). An Ergonomic Evaluation of Several Modified Pneumatic Hammers, pp. 16-18. Technical Report No. 16. Community Ergonomic Research. Document Number 1522/74. European Coal and Steel Community.
Dunham, K. C. (1949). Memoirs of the Geological Survey of Great Britain, England and Wales; Geology of the Northern Pennine Orefield. Volume 1. Tyne to Stainmoor, 1st edition, 2nd impression, pp. 4-9. HMSO: London. 1975.

Hellstrøm, B., and Myhre, K. (1971). A comparison of some methods of diagnosing Raynaud's phenomena of occupational origin. British Journal of Industrial Medicine, 28, 272-279.

Hempstock, T. I., and O'Connor, D. E. (1975). Evaluation of human exposures to hand-transmitted vibration. In Applied Acoustics, volume 8, pp. 87-97. Applied Science Publishers Ltd: England.

Hunter, D., McLoughlin, A. T. C., and Perry, K. M. A. (1945). Clinical effects of the use of pneumatic tools. British Journal of Industrial Medicine, 2, 10-16.

Hunter, D. (1969). The Diseases of Occupations, 4th edition, pp. 885-895. English Universities Press: London.

Hutchinson's Clinical Methods, 15th edition, pp. 265-270. Edited by D. Hunter, R. R. Bessford, and D. G. Penington. Baillière, Tindall and Cassell: London. 1973.

Lidström, I. M. Medical aspects of recent vibration work in Sweden. In The Vibration Syndrome, pp. 187-193. Edited by W. Taylor. Academic Press: London.

McCallum, R. I. (1971). Vibration syndrome. British Journal of Industrial Medicine, 28, 90-93.

Renfrew, S. (1969). Finger tip sensation. A routine neurological test. Lancet, 1, 396-397.

Schumacher, H. R., Agudelo, C., and Labowitz, R. (1972). Jackhammer arthropathy. Journal of Occupational Medicine, 14, 563-564.

Seyring, M. (1930). Diseases resulting from work with compressed air tools. Archiv für Gewerbepathologie und gewerbe hygiene, $1,359$.

Taylor, W., and Pelmear, P. L. (1975). Vibration White Finger in Industry. Academic Press: London. 